BLS 33, No 1 2007. DOI: http://dx.doi.org/10.3765/bls.v33i1.3522

(published by the Berkeley Linguistics Society and the Linguistic Society of America)

\title{
Marking Aspect and Mood and Inferring Time in Mam (Mayan)
}

\author{
NORA C. ENGLAND \\ University of Texas at Austin
}

Mayan languages have generally been considered to mark aspect and mood rather than tense on verbs (e.g., Kaufman 1990, Bohnemeyer 2002), or to have combined tense/aspect systems (e.g., Larsen 1988). Mam has usually been analyzed, by me and others (e.g., England 1983, Pérez and Jiménez 1997), as having a somewhat hybrid system of tense/aspect marking, with aspectual information generally more prominent than temporal information. Here I argue that morphological marking on verbs refers entirely to aspect or mood in Mam, examine how temporal information is inferred, and show how time is conveyed in texts.

\section{Background: Clause Structure}

Mam has two basic types of clauses: those headed by verbs and those headed by nonverbal predicates (statives, locatives, existentials, or equatives). Both verbs and nonverbal predicates mark their main arguments according to an ergative pattern of person agreement - the subjects of transitive verbs are indicated by one set of morphemes (Set A) while objects of transitive verbs, subjects of intransitive verbs, and subjects of nonverbal predicates are marked by another $\left(\operatorname{Set} \mathrm{B}^{1}\right)$.

$$
\begin{array}{lllll}
\text { ma } & \text { chin } & \text { etz } & \text { t-tzyu-'n-a } & \text { 'you grabbed me' } \\
\text { PROX } & \text { B1s } & \text { DIR } & \text { A2p-grab-DS-2s/1s }{ }^{3}
\end{array}
$$

\footnotetext{
${ }^{1}$ The forms of Set B that are used for the subjects of nonverbal predicates are slightly different from Set B in other contexts, but are clearly derived from Set B and not from Set A.

${ }^{2}$ Examples are from texts or my notes. If they are from texts they are followed by (T). I have used many of the examples before, principally in England 1983. Unless otherwise indicated, they are from Ixtahuacán. Symbols in the Mam alphabet used here have the expected values, except $\mathrm{VV}=$ long vowel, ' = glottal stop, $\mathrm{ch}=$ alveopalatal affricate, $\mathrm{j}=$ uvular fricative, $\mathrm{ky}=\mathrm{palatal}$ stop, $\mathrm{t} x=$ retroflexed affricate, $\mathrm{t} \mathrm{z}=$ alveolar affricate, $\mathrm{x}=$ retroflexed fricative, $\mathrm{xh}=$ alveolpalatal fricative.

3 Abbreviations are: $\mathrm{A}=$ Set $\mathrm{A}, \mathrm{ABST}=$ abstract noun, $\mathrm{AFF}=$ affirmative, $\mathrm{AGT}=$ agent, $\mathrm{AGTV}=$ agentive, $\mathrm{AP}=$ antipassive, $\mathrm{B}=\mathrm{Set} \mathrm{B}, \mathrm{CLS}=$ classifier, $\mathrm{CPL}=$ completive, $\mathrm{DAT}=$ dative, $\mathrm{DEM}=$ demonstrative, $\mathrm{DEP}=$ dependent, $\mathrm{DIR}=$ directional, $\mathrm{DISP}=$ displacement, $\mathrm{DS}=$ directional suffix, EMPH= emphatic marker, EXCL=exclusive, EXIST=existential, IMP=imperative, IMPF= imperfect, INALIEN=inalienable, INC=incompletive, INF=infinitive, INST=instrumental, MIR= mirative, $\mathrm{NEG}=$ negative, $\mathrm{NOPOT}=$ non-potential, $\mathrm{p}=$ plural, $\mathrm{PART}=$ participle, $\mathrm{PAS}=$ passive,
} 
Nora C. England

(2)

$$
\begin{array}{llll}
\text { ma } & \text { tz'-etz } & \text { n-tzyu-'n-a } & \text { 'I grabbed you' } \\
\text { PROX } & \text { B3p-DIR } & \text { A1s-grab-DS-1s/2s } &
\end{array}
$$

(3)

$\begin{array}{llll}\text { ma } & \text { chin } & \text { b'eet-a } & \text { 'I walked' } \\ \text { PROX } & \text { B1s } & \text { walk-1s } & \end{array}$
siky-naj qiin-a
'I am tired'
tire-PART B1s-1s

Split ergativity occurs in a number of different contexts, including temporal (when) clauses. In such clauses all arguments are marked ergatively. (5) gives a transitive verb with a directional where both arguments are marked ergatively, (6) is a transitive verb without a directional, and (7) is an intransitive verb.

ok t-ku'-x ky-awa-'n xjaal kjo'n... when:POT A3s-DIR-DIR A3p-plant-DS person cornfield 'When the people plant the cornfield ...'

$\begin{array}{llll}\text { Ok qo tzaalaj-al ok t-q-il } & \text { u'j } \\ \text { POT B1p } & \text { be.happy-POT when:POT A3s-Alp-see } & \text { book } \\ \text { t-e } & \text { yool t-e } & \text { I'tzal. } & \\ \text { A3s-RN:POSS } & \text { word RN:POSS } & \text { Ixtahuacán } \\ \text { 'We will be happy when we see the Ixtahuacán dictionary.' }\end{array}$

$$
\begin{aligned}
& \text { aj } \quad \text { t-qoqaax ....(T) } \\
& \text { when:NOPOT A3s-night.falls } \\
& \text { 'when night fell ...' }
\end{aligned}
$$

Verbal predicates normally ${ }^{4}$ take aspect markers, while nonverbal predicates never do. In examples (1) - (3) the verbs are marked with the proximate aspect morpheme $m a$, while the nonverbal predicate in (4) has no aspect marker. (8) shows that aspect marking is ungrammatical with a nonverbal predicate:

$$
\begin{array}{lll}
\text { *ma } & \text { siky-naj } & \text { qiin-a } \\
\text { PROX } & \text { tire-PART } & \text { B1s-1s } \\
\text { Intended meaning: 'I was tired' }
\end{array}
$$

$\mathrm{PAT}=$ patient, $\mathrm{PERF}=$ perfect, $\mathrm{PL}=$ plural, $\mathrm{POSS}=$ possessive, $\mathrm{POT}=$ potential, $\mathrm{PROX}=$ proximate, $\mathrm{REFL}=$ reflexive, $\mathrm{RES}=$ =resultative, $\mathrm{RN}=$ relational noun, $\mathrm{s}=$ singular, $\mathrm{TERM}=$ specific termination, $\mathrm{VB}=$ verbalizer.

${ }^{4}$ There are a number of contexts in which verbal predicates have no aspect marking. These include: all contexts in which there is split ergativity, after temporal adverbs, after negative or affirmative particles, and in clauses headed by the quotative verb - chi or that are headed by or are complements of the verb $-a j$ 'want'. 
Both kinds of predicates can take temporal adverbs. Their unmarked position with verbal predicates is first, where they replace aspect markers $(9 a)^{5}$. They can also be last in the clause but then require dependent aspect markers (9b). Temporal adverbs usually occur after a nonverbal predicate, but they can also occur before it, and require no structural changes in either position $(10,11)$.

(9) a. eew tz-ul aaj nan yaa'

yesterday B3s-DIR return ma'am grandmother

'Grandmother came yesterday.'

b. ø-ø-ul aaj nan yaa' eew

CPL.DEP-B3s-DIR return ma'am grandmother yesterday

'Grandmother came yesterday.'

at- $\varnothing \quad$ jun aq'uuntl ojtxa (T)
EXIST-B3s a work before
'There was work before.'

(11) ja'la aa- Ø-qa-tzan (T)

now DEM-B3s-PL-well

'well, now these are them'

\section{Aspect and Mood Marking on Verbs}

Mam has six proclitics, several suffixes, and one enclitic that together express categories of aspect or mood. The proclitics occur first in the verb and distinguish completive, incompletive, potential, and what I am calling "proximate" aspects. The completive and proximate aspects are each marked by two different morphemes, one for certain dependent clauses, the other for independent clauses.

\footnotetext{
${ }^{5}$ Adverbs such as ja'la 'now' that indicate the present in fact indicate an immediate future in first position and the present in final position: position and $t$ 'Father is coming now.'
ii. Ja'la tz-uul taat. now B3s-come father 'Now father is about to come/will come.'
$\begin{array}{lll}\text { i. Tz-uul taat } & \text { ja'la. } \\ \text { B3s-come } & \text { father now }\end{array}$
$\begin{array}{lll}\text { i. } & \text { Tz-uul taat ja'la. } \\ \text { B3s-come } & \text { father now }\end{array}$


(12) ma proximate (inceptive) action, independent clause

$\mathrm{x}-\quad$ proximate (inceptive) action, dependent clause ${ }^{6}$

o completive, independent clause

$\varnothing \quad$ completive, dependent clause ${ }^{7}$

n- incompletive (progressive, habitual)

(ok) potential

The forms with vowels are phonologically independent, while those without vowels are bound. The potential marker ok is optional, but potential is also obligatorily marked by suffixes. A default temporal context is inferred from the aspect markers. The proximate is understood as a recent past in its default interpretation, the completive is understood as an ordinary past referring to any time before the present day, the default interpretation of the incompletive is present progressive, and the potential is understood as future:

Transitive Verb

ma chi wila

'I saw them (a little while ago)'

$$
\text { xhi wila }
$$

$\mathrm{x}$-chi

'when I saw them (a little while ago)'

o chi wila

'I saw them (before today)'

ø-i wila

'when I saw them (before today)'

nchi wila

'I am seeing them, I see them'

(ok) chi wila'ya

'I will see them'
Intransitive Verb

(13') ma chin b'eeta

'I walked (a little while ago)'

(14') xhin b'eeta

$\mathrm{x}$-chin

'when I walked (a while ago)'

(15') o chin b'eeta

'I walked (before today)'

(16') ø-in b'eeta

'when I walked (< today)'

(17') nchin b'eeta

'I am walking, I walk'

(18') (ok) chin b'eetala

'I will walk'

\footnotetext{
${ }^{6}$ The dependent forms of the completive and proximate aspects are used in clauses after focused and fronted nominals or after focused time adverbs, in clauses subordinated to a clause with the imperfect $-t a q$ in the non-potential, in temporal clauses without a temporal subordinator that indicates a specific time, and after the manner adverb mes 'suddenly, unintentionally'.

${ }^{7}$ This morpheme is real. Verbs in the completive in dependent clauses lack the first consonant of Set B markers, which follow aspect marking in the verb complex. Thus chin 'first person singular' becomes in, qo 'first person plural' is $o$, chi second/third person plural is $i$, and all of the audible forms of second/third person singular $\left(t z-, t z^{\prime}-, t-\right)$ are omitted.
} 
Verbal suffixes that indicate (aspect or) mood are different depending on whether the verb is intransitive, transitive, or transitive with an accompanying directional. They mark two verbal categories: potential and imperative, and therefore are used in irrealis situations. Given that these are the only two categories that are marked with suffixes, and because the potential indicates uncertain future events, the suffixes basically mark mood in Mam. They are:

$\begin{array}{lll} & \text { Potential } & \text { Imperative } \\ \text { intransitive: } & -1^{8}, & --- \\ \text { transitive: } & -\mathrm{a} \text { ' } & -\mathrm{m} \\ \text { transitive with directional: } & -1 \text { (on directional) } & -\mathrm{n}\end{array}$

Examples are:

(ok) chin b'eetala

'I will walk'

(ok) tlaq'a'ya

'you will buy it'

(ok) ktzajal tlaq'o'na

'you will buy it'

3) b'eeta

'walk!'

q'iima

'take it!'

q'iinxa

'take it (there)!'

The enclitic $-t a q$ is the final element that marks aspect morphologically. It combines with verbs, nonverbal predicates and certain adverbs and, depending on the type of base it combines with and the aspect proclitics if the base is verbal, it indicates either perfect or imperfect. When it is combined with the aspect marker $m a$, usually with the incompletive marker $n$ - at the same time, it indicates that an action has been begun (imperfect) (26), but in combination with the completive $o$ it indicates that an action has or will have been completed with regard to some other action (perfect) (27). When $-t a q$ is combined with manner adverbs it indicates that an action has begun (imperfect) (28), but when it is combined with

\footnotetext{
${ }^{8}$ If an intransitive verb is accompanied by a directional, the potential marker goes on the directional.
} 
Nora C. England

time adverbs it indicates that some specific time has gone by (perfect) (29). With nonverbal predicates it is ambiguous; it indicates that something is in a particular state, but it is unkonown whether it still is in that state (imperfect) or it is interpreted as being in that state because it had gotten to that state (perfect). Translations reflect the ambiguity, as in (30). Thus this enclitic in general fits the perfect in terms of anteriority, but differs from it in that sometimes it indicates stativity (perfect) but sometimes it does not (imperfect).

\begin{tabular}{lccll} 
Maa-taq & n-chin & b'eet-a & s-ok & n-kii-n \\
PROX-IMPF & INC-B1s & walk-1s & PROX.DEP.B3s-DIR & A1s-see-DS \\
W-iib'-a & t-uk' & \multicolumn{2}{c}{ jun xjaal. } & \\
A1s-RN:REFL-1s & A3s-RN:with & a & person &
\end{tabular}

'I was walking when I met a person (and may have continued).'

Oo-taq ø-b'aj t-qeeta-n Luuch t-tzii'. (T)

CPL-PERF B3s-DIR A3s-cut-DSPedro A3s-mouth

'Pedro had cut their mouths (when some other event occurred).'

(28) ch'ix-taq-tzan t-pon kaana-n yaa'yj, (T) almost-IMPF-well A3s-DIR meet-AP grandmother 'the grandmother was almost on the point of arriving (she has begun the process that will lead to her arrival but has not finished)'

$\begin{array}{lll}\text { Yaa kwanda } & \text { kab'-a oora-taq ky-ku-leen } & \text { teen-q'a } \\ \text { now , when } & \text { two-? hour-PERF A3p-go.down-ABST } & \text { be-CLS } \\ \text { t-uk, } & \text { ky-q'aaq'-q'a (T) } & \\ \text { A3s-RN:with } & \text { A3p-fire-CLS }\end{array}$

'Now when two hours had passed that they spent with their fire'

$$
\begin{array}{ll}
\text { q'an-ø-taq } & \text { chulal } \\
\text { ripe-B3s-IMPF/PERF } & \text { zapote (a fruit) }
\end{array}
$$

'the zapote was ripe' or 'the zapote had ripened'

\section{More on Aspect Proclitics}

The aspect proclitics convey something of temporal information, so the question arises as to whether they are truly aspects or at least in part tenses. A more careful examination of their context of use shows that the temporal information they convey is secondary to the aspectual information and can be overridden in specific contexts. The temporal information is a matter of default inference.

The most clearly aspectual of the proclitics is $n$ - 'incompletive'. The default meaning that this marker conveys is present progressive (31). However, it is also used for ongoing habitual actions (32) and can be combined with specific time adverbs to indicate the progressive in times other than the present $(33,34)$. 
(31)

n-ø-poon a'

INC-B3s-arrive water

'the water is arriving'

nn-ø-eel ch'in-ni q-chiky'-eel ky-u'n-jal (T)

INC-B3s-go.out a.little-DIM Alp-blood-ABST A3p-RN:by-CLS

'they take a little of our blood' (speaking of fleas)

$\begin{array}{ll}\text { yaa } & \mathbf{n} \text {-ø-poon a' } \\ \text { just.now } & \text { INC-B3s-arrive water }\end{array}$

'the water was just arriving'

ojtxa n-ø-poon a'

before INC-B3s-arrive water

'the water was arriving before'

When $-n$ is used with maataq, it marks clauses in the imperfect (35).
maa-taq
n-chin yoola-n-a
xhin-tzaj
txako-'n-a
PROX-IMPF
INC-B1s talk-AP-1s
PROX.DEP.B1s-DIRcall-DS-1s
'I was talking when they called me.'

Furthermore, as will be seen in the text analysis, $n$ - is customarily used in narrative to mark progression in the text, even when there is no implication of progressive or habitual action (36).
n-ø-tzaj-tzan ky-laq'o-'
INC-B3s-DIR-well A3p-buy-DS
'so the mule-drivers bought it'
aryeeral ja'la (T)
mule.driver now

Lastly, the temporal context of other clauses in a text can determine the temporal context of $n$ - (37).
Aa-tzan $\varnothing-\varnothing-o k$
n-b'i-'n-a
kuxi'
DEM-well CPL.DEP-B3s-DIR A1s-hear-DS-1s
n-ø-jaaw nimaal. (T)
INC-B3s-go.up DEM
'According to what I heard, every little while it tore/was tearing.'

The marker $o$ indicates completed action and usually is interpreted as an ordinary past, which includes roughly anything that occurred before today (38). It can also be used for former habitual actions; that is, habitual actions in the past that have come to some conclusion or which are no longer relevant (39). 
Nora C. England

Ntii', nti' o-ø-t-maa ch'in nee'. (T)

NEG NEG CPL-B3s-A3s-say a.little small

'No, he didn't say anything.'

b'ix nim o-ø-b'eet t-witz tx'otx'. (T)

and a.lot CPL-B3s-walk A3s-RN:on land

'and he walked a lot in the countryside.'

As has been seen, $o$ in combination with -taq indicates a perfect (40). If such a form occurs with a clause in the potential, it indicates a future perfect (41).

Oo-taq ø-b'aj waa-'n ø-ø-xi q'o-'n t-k'aa'. CPL-PERF B3s-DIR eat-DS CPL-DEP-B3s-DIR give-DS A3s-drink 'He had eaten when they gave (him) his drink.'
Oo-taq $\quad$-b'aj waa-'n ok
t-tzaj
q'o-'n
t-k'aa'. CPL-PERF B3s-DIR eat-DS when.POT A3s-DIR give-DS A3s-drink 'He will have eaten when they give (him) his drink.'

Given that the use of $o$ is not confined to the past, it seems clear that it marks completive aspect rather than any tense. Its default interpretation as a past is because completed events have usually already occurred, and its default interpretation as a past that occurred before today is due to the space that is reserved by $m a$, the proximate aspect marker.

I analyzed $m a$ for many years as a recent past marker, and Pérez and Jiménez analyzed it as a recent completive marker (1997:155-156). I no longer think either statement is completely correct. It is true that the default interpretation of $m a$ is of an action that was at least begun in the recent past (any time today). For instance, a narrator of a tale says the sentence in (42) as he is finishing his story.
Aa-tzan jun kol-jo
ma-a'
$\varnothing$-txi
n-kaa'we-n-a. (T)
DEM-well a theme-DEM PROX-EMPH B3s-DIR A1s-reason-DS-1s
'Well, this is a story I just told.'

However, $m a$ does not imply that the action has necessarily ended. The clause in (43) contains an idiomatic expression for 'we understand' which literally means 'our thoughts go out'. The phrase is interpreted as a continuing process of understanding.
kee aa-tzan-jo
ma-a' tz'-eel q-niiky'
$t-i ’ j(T)$
that DEM-well-DEM PROX-EMPH B3s-go.out Alp-thought A3s-RN:theme 'well, this is what we now understand about it' 


\section{Marking Aspect and Mood and Inferring Time in Mam}

Furthermore, José Pérez says (p.c.) that if the verb is durative, then there is less security about whether the action was finished, but if the verb is punctual, then it was finished almost as soon as it began:

ma chin waa-n-e' (Cajolá dialect)

PROX B1s eat-AP-1s

'I ate' (I ate something, but may not have eaten well, or a whole meal)

$$
\begin{aligned}
& \text { ma ø-kub' n-pa-'n-e' (Cajolá dialect) } \\
& \text { PROX B3s-DIR A1s-break-DS-1s } \\
& \text { 'I broke it' (the action was completed) }
\end{aligned}
$$

The use of $m a$ with -taq emphasizes the inceptive part of its meaning, since together they indicate an imperfect meaning, as in (46), where the explanation given was that the act of speaking was beginning at the moment of being called.

$$
\begin{array}{lllll}
\text { Maa-taq n-chin } & \text { yoola-n-a } & \text { xhin } & \text { tzaj } & \text { txako-'n-a. } \\
\text { PROX-IMPF INC-B1s } & \text { speak-AP-1s } & \text { PROX.DEP.B1s DIR } & \text { call-DS-1s } \\
\text { 'I was speaking when (they) called me.' } &
\end{array}
$$

In addition, $m a$ can be used for actions that occur in the more distant past when they are being related to some other proximate event, and not just to the moment of speaking. For instance, in (47) the event that is marked by ma (sunrise) took place in the remote past of the story, but is related to the immediately consequent action of the people saying "let's go".

$$
\begin{aligned}
& \text { Ma-tzan ø-jaa'w-al } \quad \text { q'iij, “qoo-qa” } \quad \text { chi-chi-tzan xjaal. } \\
& \text { PROX-well B3s-go.up-TERM sun let's.go-1pEMPH B3p-say-well people } \\
& \text { '(When) the sun came up, "let's go" said the people.' (T) }
\end{aligned}
$$

Finally, $m a$ uncharacteristically indicates an action that is about to begin when it is used with the intransitive verb of motion $x i$ ' ' $\mathrm{go}$ ' and is ambiguous when it is used with the intransitive verb of motion $a a(n) j$ 'return there': ${ }^{9}$

$$
\begin{array}{ll}
\text { ma t-xi' } & \text { 'he will go' } \\
\text { ma tz'-aanj } & \text { 'he returned' or 'he will go (returning)' }
\end{array}
$$

The explanation for this unusual interpretation lies in the grammaticalization of the intransitive verbs of motion as directional auxiliaries on verbs. The directional $x i$ ' primarily marks trajectory ('away') but secondarily marks incipient action (aspect). Several contexts show its aspectual function. First, it is almost always used with the 'resultative' morphemes -' $k j$ 'resultative indicative' and

\footnotetext{
${ }^{9}$ Data in (48) are from José Pérez, and represent the speech of Cajolá.
} 
Nora C. England

$-b$ 'aj 'resultative passive'. These morphemes indicate that an action occurs because someone moves to do it. Thus (49) indicates that the fox went somewhere to bite something:

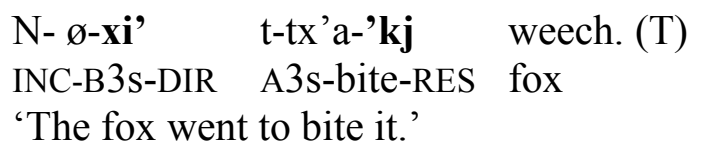

$X i$ ' is also often used with the potential, even when the verb does not necessarily require this directional. Compare the directional in (50b) with that in (50d). The verb is the same, but when it is in the potential the narrator uses $x i^{\prime}$ ' while when it is not in the potential she uses $k u$ '.

(50)a. At- $\varnothing \quad$ jun kweent ( $\mathrm{T})$

EXIST-B3s a story

'There is a story'

b. ø-x-el n-q'ama-'n-a ja'la, B3s-DIR-POT A1 s-tell-DS-1s now 'that I will tell now,'

c. at- $\varnothing$ jun t-yool n-yaa'-ya

EXIST-B3s a A3s-word A1s-grandmother-1s

'it is a story of my grandmother's'

d. ø-ø-ku' t-q'ama-'n t-uk'u-x n-txuu-ya.

CPL.DEP-B3s-DIR A3s-tell-DS A3s-RN:with-alwaysA1s-mother-1s

'that she told with my mother.'

$X i$ ' is also used by itself to indicate incipient action. In (51) the verb 'hide' is not a separate predicate (for instance, an infinitive) in Mam, and the directional serves to indicate that the subject has initiated the action of hiding.

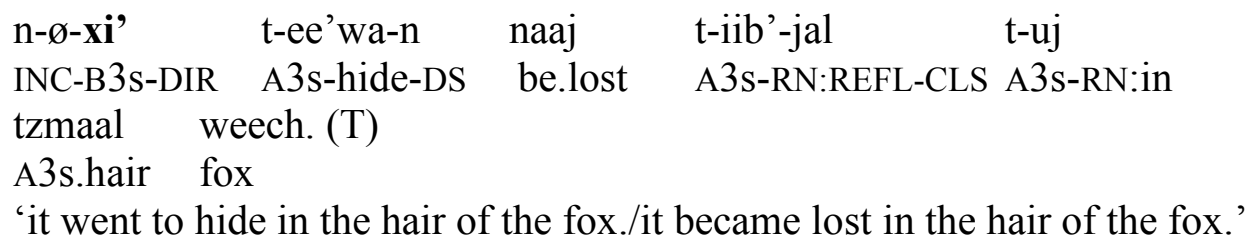

The aspectual meaning of $x i$ ' thus overrides that of $m a$. Presumably $a a(n) j$ behaves like $x i$ ' because it overlaps in meaning ('return there' means 'go returning'). Since the meaning overlap is partial, this leads to an ambiguous interpretation of $m a+a a(n) j$. 


\section{Marking Aspect and Mood and Inferring Time in Mam}

In summary, $m a$ does not always indicate completed action and it does not always indicate recent action as measured from the moment of speaking. Its meaning seems to center more on actions that have begun (or are about to begin) and that are proximate to some event that is not necessarily the act of speaking. I have chosen to label it 'proximate' in accordance with what seems to be its most prominent meaning.

The potential is optionally marked with the proclitic $o k$ and obligatorily marked with a suffix on the verb stem or on an associated directional. There is very little to distinguish the potential from a future tense, except that, as shown, some uses of $m a$ imply an immediate future, so not all of the possible 'future' space is marked by the potential markers. Furthermore, as has been seen, future completives are indicated by ootaq rather than a potential marker. Thus both the completive and the proximate markers can make reference to future events in certain contexts. Therefore the better descriptive term for these morphemes is 'potential'. This is the only proclitic that is optional and is paired with a required suffix. This may reflect its ambiguous status - on the one hand it conveys something of aspect, like the other proclitics, but on the other hand it conveys something of mood, like the other suffixes. (52) provides an example of the potential.

$$
\begin{aligned}
& \text { tqal-tzan k- } \varnothing-t-a q '-a l-a \\
& \text { what-well POT-B3s-A2s-give-POT-2s A1p-RN:DAT-1pEXCL } \\
& \text { 'what will you give us?' }
\end{aligned}
$$

It has been demonstrated that each of the aspect proclitics principally marks aspect (or mood) and not tense. Temporal information that is conveyed by these markers results from inference, or is only partial, and in several instances is overridden by contextual factors. None of the markers corresponds to a definite and well-defined temporal interval. (53) summarizes the information that has been

\begin{tabular}{|c|c|c|c|c|c|c|}
\hline proclitic & aspect & $\begin{array}{l}\text { default } \\
\text { temporal } \\
\text { meaning }\end{array}$ & other meanings & + -taq & $\begin{array}{l}+ \text {-taq }+ \\
\text { pot. } \\
\text { clause }\end{array}$ & $\begin{array}{l}+x i \\
a a(n) j\end{array}$ \\
\hline $\mathrm{n}-$ & incompletive & $\begin{array}{l}\text { present } \\
\text { progressive }\end{array}$ & $\begin{array}{l}\text { progressive in } \\
\text { other times, } \\
\text { progression in } \\
\text { text, } \\
\text { ongoing habitual }\end{array}$ & $-\cdots$ & $-\cdots$ & no effect \\
\hline o/ø & completive & past & $\begin{array}{l}\text { completed, past } \\
\text { habitual }\end{array}$ & perfect & $\begin{array}{l}\text { future } \\
\text { perfect }\end{array}$ & no effect \\
\hline $\mathrm{ma} / \mathrm{x}-$ & proximate & recent & $\begin{array}{l}\text { proximate to } \\
\text { some other } \\
\text { event, inceptive }\end{array}$ & $\begin{array}{l}\text { imperfect } \\
( \pm n-)\end{array}$ & -- & $\begin{array}{l}\text { future } \\
\text { (inceptive) }\end{array}$ \\
\hline $\begin{array}{l}\text { (ok) }+ \\
\text { suffixes }\end{array}$ & potential & future & may occur & $-\cdots$ & $-\cdots$ & no effect \\
\hline
\end{tabular}
presented about the aspect markers.

(53) Uses of Aspect Proclitics 
Nora C. England

\section{More on Aspect and Mood}

In addition to the suffixes on verbs there are two other classes of function words in Mam that indicate mood (understood here as imperative and potential): negative particles and two of the temporal subordinators. Verbal predicates are negated by mii'n in the imperative and potential, without the potential proclitic $(54,55)$, but are negated by $n t i$ ' along with other aspect markers in the nonpotential (56).

$$
\begin{aligned}
& \text { Mii'n ø-tzaaj jb'aal ja'la. } \\
& \text { NEG B3s-come rain today } \\
& \text { 'It will not rain today.' }
\end{aligned}
$$

$$
\begin{aligned}
& \text { Mii'n b'eet-a. } \\
& \text { NEG walk-2s } \\
& \text { 'Don't walk!' }
\end{aligned}
$$

$$
\begin{array}{llll}
\text { Nti' } \quad \text { o } & \text { tz'-e-tz } & \text { n-laq'o-'n-a. } \\
\text { NEG } \quad \text { CPL } & \text { B3s-DIR-DIR } & \text { A1s-buy-DS-1s } \\
\text { 'I didn't buy it.' } &
\end{array}
$$

Mam has four temporal subordinators ('when'), two of which make a distinction between potential and nonpotential. $O k$ is used in the potential (57), while $a j$ is used in the nonpotential (58). The other two, ela' and kwanto/kwando, are used in any aspectual or temporal context; the default sense is completive $(59,60)$. In general, the 'when' clause does not take aspect proclitics and shows split ergativity (the verb is marked with all ergative markers for person). However, there are two exceptions to this generalization. A clause with aj can co-occur with the incompletive marker in a generic statement (61), and a clause with kwanto can occur optionally with aspect proclitics (62). In either case, if there is an aspect proclitic, agreement is the normal ergative pattern. An explicit subordinator is not required in a temporal clause; any clause without an aspect marker and with split ergativity is understood as a 'when' clause (63).

$$
\begin{aligned}
& \text { Ok } \quad \text { t-b'ant } \quad \text { ky-k'ooj-a... (T) } \\
& \text { when:POT A3s-make } \\
& \text { 'W2p-mask-2p } \\
& \text { 'When your masks are made. ..' }
\end{aligned}
$$

$$
\begin{aligned}
& \text { O ø-tzaalaj xjaal t-i'j t-paa aj } \\
& \text { CPL B3s-be.happy person A3s-RN:theme A3s-bag when:NOPOT } \\
& \text { t-kan-eet priim-x. } \\
& \text { A3s-find-PAS early-still } \\
& \text { 'The person was happy about his bag when it was found early.' }
\end{aligned}
$$


Ela t-b'aj meq't $n-\varnothing-x i$ t-waa'-n xjaal. when A3s-DIR heat INC-B3s-DIR A3s-eat-DSperson 'When he finished heating (it), the person ate it.'

Entoonse kwanda-tzan t-eel t-pokb'-aal... (T) then when-well A3s-go.out A3s-explain-ABST 'Well, when the news went out. ..'
Aj
nti' n-qo-kaamb'a-n t-i'j
scha-b'al
when:NOPOT NEG INC-B1p-win-AP A3s-RN:theme play-INST
n-qo-jaw b'iisa-n.
INC-B1p-DIR sad-AP
'When we don't win the game we are sad.'

Kwanto s-ook-1 tzluu'... when PROX.DEP.B3s-enter-DIR here

'When it got here. ..'

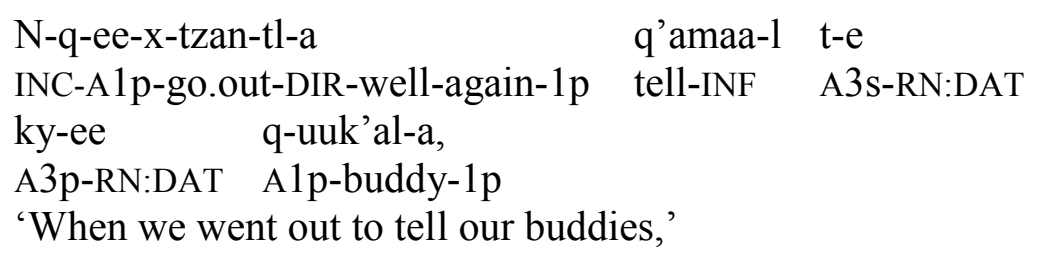

The negatives and temporal subordinators make a clear distinction between irrealis and realis; the same distinction that is made by the intersection of aspect proclitics and mood suffixes in Mam. The table in (65) summarizes the aspect and mood categories in Mam.

(64) Aspect and Mood

\begin{tabular}{|l|l|l|l|l|l|}
\hline & & proclitic & suffix & negative & 'when' \\
\hline \multirow{3}{*}{ irrealis } & imperative & no & yes & mii'n & - - - \\
\cline { 2 - 6 } & potential & optional $o k$ & yes & mii'n & ok \\
\hline \hline \multirow{3}{*}{ realis } & completive & $o / \varnothing$ & no & nti' & aj \\
\cline { 2 - 7 } & incompletive & $n-$ & no & nti' & aj \\
\cline { 2 - 6 } & proximate & $m a / x-$ & no & nti' & aj \\
\hline
\end{tabular}

\section{Time in Discourse}

Mam is not a tensed language. In addition to the fact that all of the morphological markers that have something to do with time indicate either aspect or mood, these markers are not required in all clauses. Nonverbal predicates have no aspect or mood marking, except for -taq. Verbal predicates in a number of different contexts also lack aspect or mood marking. In fact, in a count of 706 clauses in four 
narrative texts, only $42 \%$ had aspect or mood marking at all, and only $4 \%$ of the remaining clauses had time adverbs, leaving $54 \%$ of the clauses without any marking for time. Furthermore, over half of the clauses with aspect or mood marking were marked with the incompletive aspect proclitic, the least temporally explicit of the proclitics. If only verbal clauses are considered, then $45 \%$ of these still lack aspect/mood marking, and only $3 \%$ have time adverbs.

The question then becomes: how is time indicated, inferred, or understood in discourse? Here I will limit my analysis to narrative. The only mechanisms for directly indicating time are lexical. One of the temporal adverbs, ojtxa 'before, a long time ago' has the special function of introducing all narratives of the folktale type. This adverb will always be used within the first few clauses of the story, and signals the type of tale as well as situating it in the distant past. In this context it is equivalent to 'once upon a time'. In example (65) it appears in the first clause of a folktale and in (66) it appears in the second clause of another story. ${ }^{10}$

$$
\begin{array}{lll}
\text { Juun } & \text { xjaal- } \varnothing \text { ojtxa Luuch- } \varnothing \text { t-b'ii, (T1) } \\
\text { a } & \text { person-B3sbefore Pedro-B3s A3s-name }
\end{array}
$$

'Once upon a time there was a person named Pedro,'

(66)a. Chi-chi-tzan xjaal, B3p-say-well person 'The people tell'

b. tza'n $\quad$ - $\varnothing$-kan-eet axi'n ojtxa. (T4)
how CPL.DEP-B3s-find-PAS corn before
'how corn was found once upon a time.'

Once the temporal context of a story has been established with ojtxa, that context is maintained in succeeding clauses and in fact throughout the tale. In general most clauses in the narrative that are marked for aspect use the incompletive marker $n$-. For instance, after the introduction to a text about an orphan in which the remote context is established, the first section begins with a nonverbal predicate $(67 \mathrm{a})$, continues with two clauses in the incompletive (b, c), which are then followed by a set of three clauses with nonverbal predicates $(\mathrm{d}, \mathrm{e}, \mathrm{f})$, and then the section ends with three more clauses in the incompletive ( $g, h, i)$.

$$
\begin{aligned}
& \text { (67)a. Kye at- } \varnothing \text { jun meeb'a, } \\
& \text { that EXIST-B3s a orphan } \\
& \text { 'There was an orphan,' }
\end{aligned}
$$

\footnotetext{
${ }^{10}$ The texts that are cited in this section are four folktales, for convenience identified as T1, T2, $\mathrm{T} 3$, and $\mathrm{T} 4$, and a long conversation (T5).
} 
b. n- $\varnothing-x i$ pasyaa'ra-l t-uj tzii' maar. INC-B3s-go spend.time-INF A3s-RN:in A3s.RN:edge sea 'who went to spend time at the edge of the sea.'

c. Entoonse n-ø-xi' t-ki-’n then/so INC-B3s-DIR A3s-see-DS 'Then he saw'

d. at- $\varnothing$ jun tal alemaj, EXIST-B3s onesmall animal 'that there was a small animal,'

e. per masaat-ø t-b'ii, but deer-B3s A3s-name 'called a deer,'

f. t-ø-a' t-uj xjaaw.

EXIST-B3s-DISP A3s-RN:in moon 'that was in the moon.'

g. Entoons despwees n- $\varnothing-k u$ ' t-pensaa'ra-n t-i'j, then/so then INC-B3s-DIR A3s-think-DS A3s-RN:theme 'So then he thought about it,'

h. entoons $\mathbf{n}-\varnothing-x i$ '-tzan, then/so INC-B3s-go-well 'so he went,'

i. n-ø-xi' uub'a-l t-e t-ee, tal INC-B3s-go shoot.with.blowgun-INF A3s-RN:PAT A3s-RN:PAT small masaat t-uj xjaaw. (T3) deer A3s-RN:in moon.

'he went to shoot it, the small deer in the moon.'

Clearly not all of the clauses marked with the incompletive refer to progressive or habitual actions. The verb can refer to a durative action, as in $(67 \mathrm{~g})$, but it can also refer to a punctual action, as in (68), where a progressive interpretation is not permitted and where the action is a one-time event and clearly not habitual.

(68) N-ø-xi' ky-xoo'-n xjaal squk' t-i' weech, (T4) INC-B3s-DIR A3p-throw-DS person louse A3s-RN:on fox 'The people threw the louse on the fox,' 
What is in process is the narrative itself. The use of the incompletive in most of a narrative (any kind of narrative, not just folktales) indicates that the narration is developing little by little and is still progressing.

Another lexical mechanism that helps develop the narrative is the use of conjunctions. Some, such as b'ix 'and' or per 'but', usually indicate overlapping, simultaneous, or time irrelevant events, as in (69c) and (d). The pot is boiling at the same time that the protagonist is meeting the mule-drivers, and also at the same time there isn't any firewood or fire under it.

$\begin{array}{lll}\text { At-ø-tzan } & \text { juun } & \text { q'iij } \\ \text { EXIST-B3s-well } & \text { one } & \text { day } \\ \text { 'Well, one day' } & & \end{array}$

b. n-ch-ok nooj txqan aryeeral t-witz t-miij b'ee, INC-B3p-DIR fill group mule.driver A3s-RN:on A3s-middle road 'he met a group of mule-drivers in the middle of the road,'

c. b'ix luu n-ø-loqa-n t-xaar and DEM INC-B3s-boil-AP A3s-pot 'and there his pot was boiling'

d. per nti'-ø sii' b'ix-mo q'aaq' t-i'j, but NEG-B3s firewood and-or fire A3s-RN:for 'but there wasn't any firewood or fire for it,'

e. t-jon-aal-x xaaq $n-\varnothing-l o q a-n \quad$ weena. (T1) A3s-one-ABST-alone pot INC-B3s-boil-AP a.lot 'the pot was boiling a lot by itself.'

Sequences of events are indicated by other conjunctions, such as despwees 'then, after' (70) and entoonsa 'then, so', or the enclitic -tzan 'then, well' (70, 71) which functions exactly like the borrowed word entoonsa and is often adjoined to it. It marks the continuation of a text when there is a change of topic or activity, and indicates that the new activity follows after the previous activity. For instance, in example (71) the narrator of this story shifts from talking about one of the protagonists, Pedro, to talking about the others, the mule-drivers.

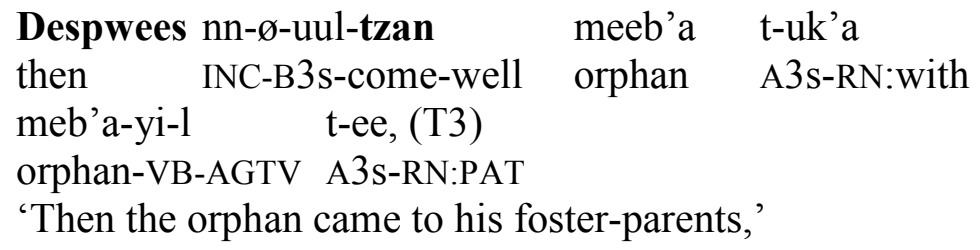


(71) In the preceding clauses, Pedro ties himself in a sack with the cord at his head. Then:

N-chi tzaj-tzan yoqpaj aryeeral (T1)

INC-B3p DIR-then gather mule-driver

'Then the mule-drivers gathered together'

However, there need not be an explicit marker for the sequencing of events. Normally, if no indication to the contrary is given, an event in a clause is understood to temporally follow the event in the preceding clause. (72) contains a series of clauses, all marked with the incompletive, in which part of the process of building a piped water system is described; each action is understood to follow after the preceding action.

(72)a. aa-tzan $\mathbf{n}$-ø-xi'-tzan q-ii-'n jun rooye mangeer, DEM-well INC-B3s-DIR-well A1p-take/bring-DS a roll hose 'we took a roll of hose,'

b. n-ø-ku'-x-tzan q-maqu-'n-a, INC-B3s-DIR-DIR-well A1p-bury-DS-1pEXCL '(and then) we buried it,'

c. n-ø-poon-tzan ch'iin a', (T5)

INC-B3s-arrive.here-well a.little water '(and then) a little water arrived,'

There are times when the action in one clause does not follow that of the previous clause. In these instances, the perfect marker, oo $+-t a q$ is used to show that the expected order of events does not apply, as in (73) and (74).

(73)a. n-ø-xi' ky-xoo-'kj t-uj a', INC-B3s-DIR A3p-throw-RES A3s-RN:in water 'they went to throw it (the sack) in the water,'

b. b'ix oo-taq-pa-la ø-jaa-tz Luuch t-uj saaka, (T1) and CPL-PERF-hasta-MIR B3s-go.up-DIR Pedro A3s-RN:in sack 'and Pedro had gotten out of the sack,' (before it was thrown in the water)

(74)a. nti'-ø-tl ky-b'aq' ky-witz, NEG-B3s-other A3p-seed A3p-face 'they didn't have their eyes,' 
Nora C. England

b. oo-taq ø-jaa-tz t-b'aq' ky-witz t-u'n

CPL-PERF B3s-go.up-DIR A3s-seed A3p-face A3s-RN:AGT

xk'otk'aj witz (T2)

"eye.taker"

'the eye-taker had taken out their eyes,' (by when they didn't have them)

Furthermore, some clauses are marked to show that an event depends more specifically on the occurrence of another event, in which instance a 'when' clause is used. In (75) the speaker is saying that the action in the second clause depends on completing the action in the first clause.

(75)a. Ok t-b'ant ky-kooj-a,

when:POT A3s-make A2p-mask-2p

'When your masks are made,'

b. esta ween qo taan-x-tzan. (T2)

it.is good B1p sleep-always-well

'we can sleep.'

Temporally dependent clauses usually do not take any aspect markers, as has been seen. Another way to indicate that one action is temporally consequent on another is by using the proximate aspect $m a$. By inserting $m a$ into a section of discourse that is otherwise marked by the incompletive $n$ - or some other aspect, the speaker shows that the event in the clause with $m a$ is more proximate to the events in another clause. For instance, in the segment in (76) the first clause is marked with the incompletive $n$-, as is typical of narratives in process, but the second is marked with the proximate $m a$, showing that what the protagonist found in the third clause is consequent on her arrival in the second.

(76)a. nn-ø-el tzoqpaj Xpi'xhlo-l kab' t-iiyaj.

INC-B3s-DIR escape Xpi'xhsee-INFtwo A3s-seed

'Xpi'xh went to look for some seeds.'

b. Ma-ø-kaana-n Xpi'xh, PROX-B3s-find-AP Xpi'xh

'(When) Xpi'xh arrived,'

c. tii noq ni mu'p-ø-ta, (T4)

that only DIM dust-B3s-3sEMPH

'there was only a little dust,'

In narrations of stories, there are two contexts in which the narrative is interrupted: for the insertion of quoted dialogue (stylistically required) or the insertion of commentary by the narrator. In both of these situations the time frame shifts 


\section{Marking Aspect and Mood and Inferring Time in Mam}

from that of the narrative in general to that of the presumed moment of speech in the quote or the actual moment of speech in a commentary. Typically, aspect or mood markers in their default temporal interpretations are used in these segments, clearly setting them off from the narrative itself, which is mostly in the incompletive. In example (77) the quote uses the potential in the first clause and the imperative in the second. In (78) the first clause is marked with the proximate aspect, as is the second, since they refer to the result of an event that had just happened when the quoted segment was spoken.

(77)a. “Qa $\quad$-x-el ky-laq'o-'n-a,

if B3s-DIR-POT A2p-buy-DS-2p

' "If you want to buy it,'

b. ø-ky-laq'oo-n-x-a!” (T1)

B3s-A2p-buy-IMP-DIR-2p

'buy it!"',

(78)a. “Aj ma-a'-1-pa tz-iky' w-n-yaab' t-i'j,

DEM PROX-EMPH-MIR-evenB3s-pass 1sEMPH-A1s-illness A3s-RN:theme

، 'Now I'm bored with this,'

b. ma-a'-l-pa tz'-ok-b'aj w-n-tzii'-ki-na,

PROX-EMPH-MIR-even B3s-DIR-finish 1sEMPH-A1s-mouth-?-AFF

"even my beak has been used up,", (T4)

In commentary by the narrator, aspect and mood markers other than the incompletive are used where appropriate. In (79) the perfect is used in the first clause and the completive in the following clauses, since the actions in the story are in the past with respect to the moment of telling and commenting about it. In (80) the commentary starts out with a potential marker (b) and continues in c) with no aspect marking and d) with the incompletive to indicate a habitual action.

(79)a. b'ix aa-l-pa-la-jo oo-taq $\varnothing-k u$ '-x t-tetz'o-'n and DEM-?-until-MIR-DEMCPL-PERF B3s-DIR-DIR A3s-insert-DS

Luuch t-uj-aj saaka

Pedro A3s-RN:in-DEM sack

'and that was because Pedro had put them in the sack,'

b. ø-ø-xi' ky-xoo-'kj xjaal.

CPL.DEP-B3s-DIR A3p-throw-RES person

'that the people went to throw.' 
Nora C. England

c. Noq-tzan ø-i-jaw mees-j only-well CPL.DEP-B3p-DIR surprise-PAS 'Well, they were surprised'

d. b'ix o-i-jaw ooq' t-i'j and CPL.DEP-B3p-DIR cry A3s-RN:theme A3p-rope 'and cried about their ropes.'

(80) The people have spoken to the flea to convince it to follow the fox and discover where it is getting corn. The flea has bargained for a little human blood in payment. (T4)

a. Toons n- $\emptyset$-tzaaj, then INC-B3s-come 'Then he came,'

b. aax-tzan $\emptyset$-x-el q-na-'n t-i'j, same.well B3s-DIR-POT A1p-think-DS A3s-RN:theme 'we will think the same,'

c. ax b'a'n ky-ky'aq chi-choo-n q-i'j, also good A3p-flea B3p-eat-AP A1p-RN:PAT 'and the fleas eat us,'

d. nn- $\emptyset$-eel ch'in-ni q-chiky'-eel ky-u'n-jal. INC-B3s-go.out a.little-DIM A1p-blood-ABST A3p-RN:AGT-CLS 'they take a little of our blood.'

Finally, when an episode of a story or the whole story ends, the narrator usually marks the end by switching back into some aspect other than incompletive. Sometimes a simple ending phrase that is marked with the completive is used, as in (81). At other times the ends of stories may have complex conclusions, but there will always be a clause marked with a non-incompletive aspect $(82,83)$.
b'ala ax
o-ø-b'ant
iky-jo, (T1)
maybe the.same CPL-B3s-do
like.this-DEM
'maybe it happened like that,'

(82)a. Aa-ø-tzan jun kol-jo

DEM-B3s-well a theme-DEM

'Well, this is a theme' 


\section{Marking Aspect and Mood and Inferring Time in Mam}

$\begin{array}{lll}\text { b. ma-a' } & \text { ø-txi } & \text { n-kaa'we-n-a. (T2) } \\ \text { PROX-EMPH } & \text { B3s-DIR } & \text { A1s-reason-DS-1s } \\ \text { 'that I just narrated.' } & \end{array}$

(83)a. o'kx-san ø-teen-jo

only-well B3s-be-DEM

'only this'

b. ø-X-el n-q'ama-'n-a. (T3)

B3s-DIR-POT A1s-say-DS-1s

'is what I will say.'

\section{Conclusions}

To summarize, Mam marks aspect and mood on verbs and in part through predicate negatives and temporal subordinators. A distinction is made between irrealis, which includes potential and imperative, and realis, covering completive, incompletive, and proximate. Time is inferred from aspect, unless it is indicated directly by time adverbs, which are, however, not very frequent. The default temporal inferences are future with the potential, present progressive with the incompletive, recent past with the proximate, and ordinary or remote past with the completive marker. Temporal overlap or simultaneity is shown by the use of conjunctions, especially b'ix 'and', and temporal sequencing is shown by other conjunctions, including despwees 'after, then', entoonsa 'then', and -tzan 'then, well'. The proximate aspect $m a$ also indicates a temporal connection between two clauses, where the second clause is consequent on the action in the first clause, marked with ma. The perfect ootaq marks temporal inversion. Clauses that are unmarked or only marked with the incompletive $n$ - are interpreted in linear order; the action in each follows the action in the preceding clause.

Whenever the temporal context is established through a direct marker such as an adverb or the default interpretation of an aspect marker, that context holds over a number of clauses, until it is changed by some other specific marker. In stories, the remote past that is established in the opening lines holds for the entire story and may never need to be reestablished. Narratives of any sort typically use the incompletive after the temporal context is established at the beginning, interrupting it only as necessary to establish more local temporal dependencies. Mam has plenty of resources to establish and maintain temporal context, without tense.

\section{References}

Bohnemeyer, Jürgen. 2002. The grammar of time reference in Yukatek Maya. Lincom Studies in Native American Linguistics 44. Muenchen: Lincom Europa. 
Nora C. England

England, Nora C. 1983. A Grammar of Mam, a Mayan Language. Austin: University of Texas Press.

Kaufman, Terrence. 1990. Algunos rasgos estructurales de los idiomas mayances, con referencia especial al K'iche'. In N. England and S Elliott, eds., Lecturas sobre la lingüística maya, 59-114. Antigua, Guatemala: CIRMA.

Larsen, Thomas W. 1988. Manifestations of Ergativity in Quiché Grammar. Ph.D. diss., University of California, Berkeley.

Pérez, (B'aayil) Eduardo and (Ajb’ee) Odilio Jiménez. 1997. Ttxoolil qool Mam: Gramática Mam. Guatemala City: Cholsamaj.

Nora C. England

University of Texas at Austin

1 University Station B5100

Austin TX 78712-0198

nengland@mail.utexas.edu 